\section{(6) OPEN ACCESS}

\title{
Heat-not-burn tobacco product use in Japan: its prevalence, predictors and perceived symptoms from exposure to secondhand heat-not-burn tobacco aerosol
}

\author{
Takahiro Tabuchi, ${ }_{5}^{1}$ Silvano Gallus, ${ }^{2}$ Tomohiro Shinozaki, ${ }^{3}$ Tomoki Nakaya, ${ }^{4}$ \\ Naoki Kunugita, ${ }^{5}$ Brian Colwell ${ }^{6}$
}

- Additional material is published online only. To view please visit the journal online (http://dx.doi.org/10.1136/ tobaccocontrol-2017-053947).

${ }^{1}$ Cancer Control Center, Osaka International Cancer Institute, Osaka, Japan

${ }^{2}$ Department of Epidemiology, Laboratory of Lifestyle Epidemiology, Istituto di Ricerche Farmacologiche 'Mario Negri', Milan, Italy ${ }^{3}$ Department of Biostatistics, School of Public Health, The University of Tokyo, Bunkyo-ku, Tokyo, Japan

${ }^{4}$ Department of Geography, College of Letters, Ritsumeikan University, Kita-ku, Kyoto, Japan ${ }^{5}$ Department of Environmental Health, National Institute of Public Health, Wako City, Saitama, Japan

${ }^{6}$ School of Public Health, Texas A\&M University, College Station, Texas, USA

\section{Correspondence to} Dr Takahiro Tabuchi, Cancer Control Center, Osaka International Cancer Institute, Chuo-ku, Osaka 541-8567, Japan;

tabuti-ta@mc.pref.osaka.jp

Received 14 July 2017 Revised 28 October 2017 Accepted 2 November 2017 Published Online First 16 December 2017

\begin{abstract}
Objectives A heat-not-burn (HNB) tobacco product, IQOS, was first launched in Japan and Italy as test markets and is currently in commerce in 30 countries. Using two data sources, we examined interest in HNB tobacco (IQOS, Ploom and glo), its prevalence, predictors of its use and symptoms from exposure to secondhand HNB tobacco aerosol in Japan, where HNB tobacco has been sold since 2014 .
\end{abstract}

Methods Population interest in HNB tobacco was explored using Google search query data. Prevalence of HNB tobacco current use (ie, use in the previous 30 days) was calculated using a longitudinal internet survey of 8240 individuals (15-69 years old in 2015) followed up to 2017. Rates of perceived symptoms from exposure to exhaled aerosol of others' HNB tobacco were also calculated.

Results The largest internet search volume for IQOS occurred in April 2016 in the week after a popular national entertainment TV show introduced IQOS. For Ploom and glo, search volumes have remained limited since their launch. Prevalence of IQOS users increased from $0.3 \%$ in January-February 2015 to $0.6 \%$ in January-February 2016 and up to $3.6 \%$ in January-February 2017, while estimated rates of use of other HNB tobacco products remained low in 2017. Respondents who had seen the TV programme in 2016 were more likely to have used IQOS than those who had not seen it (10.3\% vs $2.7 \%)$. Among never-smokers who had been exposed to secondhand HNB tobacco aerosol, nearly half reported at least one acute symptom, although these symptoms were not serious.

Conclusions A popular TV programme triggered IQOS diffusion in Japan. Extrapolating from survey results to the general population, around 3.1 million people currently use IQOS in Japan. Tobacco control organisations and governments should closely monitor HNB tobacco and consider how to regulate it.

\section{INTRODUCTION}

Heat-not-burn (HNB) tobacco products are electronic devices that heat tobacco leaf and resemble electronic cigarettes (e-cigarettes) in terms of producing aerosol. ${ }^{1}$ In 2014, Philip Morris International (PMI) introduced the IQOS, a novel HNB tobacco product in Japan and Italy only. As of October 2017, IQOS is currently being test-marketed in 30 countries, that is, Canada, Colombia, Czech Republic, Denmark, France, Germany,
Greece, Guatemala, Italy, Israel, Japan, Kazakhstan, Korea, Lithuania, Monaco, the Netherlands, New Zealand, Palestine, Poland, Portugal, Romania, Russia, Serbia, Slovak Republic, Slovenia, South Africa, Spain, Switzerland, Ukraine and the UK. ${ }^{2}$ IQOS is intended to compete with available electronic nicotine delivery systems, or e-cigarettes, ${ }^{34}$ and other HNB tobacco products. Japan is the only country where a national roll-out of IQOS has occurred, and Japan's worldwide share of IQOS was 98\% in October 2016. Japan Tobacco began 'Ploom' sales online in December 2013 and launched a new product 'Ploom Tech' in March 2016 in Japan. British American Tobacco also began to sell an HNB tobacco product 'glo' in December 2016 in Japan. During recent decades, smoking prevalence in Japan has declined from $48 \%$ in 2001 to $31 \%$ in 2016 among men, and from 14\% in 2001 to $10 \%$ in 2016 among women. ${ }^{6}$ In this circumstance, tobacco company executives are counting on HNB tobacco for significant revenue growth worldwide. $^{7}$

In December 2016, PMI applied to the US Food and Drug Administration (FDA) for IQOS to be considered a modified risk tobacco product (MRTP).$^{8}$ MRTPs are 'tobacco products that are sold or distributed for use to reduce harm or the risk of tobacco-related disease associated with commercially marketed tobacco products'. move was followed in March 2017 by a Premarket Tobacco Product Application to the FDA; this is the mechanism through which new tobacco products are authorised to be marketed in the USA.

Mass media influence people's behaviour through direct and indirect product marketing. ${ }^{10}{ }^{11}$ In Japan, HNB tobacco IQOS was picked up on a popular TV programme Ame-talk in April 2016, in which many popular Japanese comedians discussed their IQOS use, which seems to have led to interest in the product by viewers. The market share of IQOS-specific tobacco sticks has increased in Japan, reaching $4.9 \%$ of all tobacco products, including combustible cigarettes, by October $2016 .^{5}$ In an earlier study of $\mathrm{HNB} / \mathrm{e}$-cigarette use in Japan, ${ }^{12} 6.6 \%$ had ever used the product(s) and 1.3\% had used in the previous 30 days. Among electronic smoking device ever-users, e-cigarettes accounted for the majority; Ploom and IQOS only accounted for $7.8 \%$ and $8.4 \%$, respectively, in $2015 .^{12}$ 
This study examined the present state of HNB tobacco and e-cigarette use in Japan-population interest, rate of use, predictors of use and effects of use on others-based on data from two sources: Google Trends and a longitudinal internet survey in Japan.

\section{METHODS AND DATA SOURCES Google Trends}

Google Trends (www.google.com/trends), a publicly available, objectively evaluable record of search activity, calculates relative search volume (RSV) for specific search terms and has been used to assess e-cigarettes' popularity by measuring the fraction of searches that include a specific search term or terms in a user-chosen location ${ }^{13}{ }^{14}$ (in the case of the present study, Japan, where $83 \%$ of the population had internet access in 2015 and Google had the top share of desktop searches of $67 \%$ in $2016^{15} 16$ ) during a set period (the 4 years from 1 April 2013 to 1 April 2017) relative to total searches in that period, normalised to a 0-100 scale. Weekly aggregated search query trends originating in Japan were analysed to examine population interest in HNB tobacco/e-cigarettes. The search terms used included 'e-cigarettes', 'Ploom', 'IQOS' and 'glo' (irrespective of capitalisation). Because both Japanese characters and Roman letters were used to write search terms, RSVs from both were combined for given terms and normalised; that is, Japanese ' $P$ イコス(IQOS)' was combined with Roman 'IQOS'. ${ }^{13}$ Similarly, the terms ‘プルーム(Ploom)' and 'グロー(glo)' were used. Three Japanese terms ‘電子タバコ(e-cigarette)’，“電子たばこ(e-cigarette)' and 'ベイパー(vaping)' were used for e-cigarettes. We did not use search terms of specific brand names such as Blu, because e-cigarettes with nicotine are illegal and uncommon in Japan. To examine trends over time, we focused on RSV values as the impact point ${ }^{13}$; high spikes were detected by visual inspection, and RSVs ranging from 0 to 100 were evaluated as continuous values. ${ }^{14}$ Using those values, we looked for possible relationships between the RSVs (assumed to represent population interest in specific search terms) and tobacco-related events in Japan.

\section{Longitudinal internet survey}

We conducted a baseline internet survey between 31 January and 17 February 2015, randomly sampling members from a large panel with a major Japanese internet research agency, Rakuten Research. ${ }^{17}$ The overall size of the survey panel was 2278733 people in 2015 . The panel members covered all social categories (such as education, housing tenure and marital status) defined by the census in Japan. The survey panel consisted of people recruited initially through services managed by the research agency group. At the time of registration, they were required to provide information such as sex, age, occupation and residence and to agree that they would participate in different research surveys. The 2015 baseline survey recruited 8240 eligible respondents aged 15-69 years (4084 men and 4156 women) using inverse probability weighting (IPW) for 'being a respondent in an internet survey', approximating a nationally representative sample; weighting accounted for baseline characteristics such as sociodemographic, health-related and tobacco-related factors. ${ }^{12}{ }^{18}$ Details were given in a previous report. ${ }^{12}$

One-year and 2-year follow-up surveys were conducted from 29 January to 15 February 2016 and from 27 January to 27 February 2017, respectively, using the 2015 baseline survey respondents. In all, 5403 and 4304 respondents answered the follow-up surveys, for response rates of $65.6 \%$ and $52.2 \%$, respectively. After exclusion of those whose responses showed unnatural discrepancies (eg, respondents who chose the same number in all of a set of questions; other examples are shown in the online supplementary data), we analysed the remaining 5366 and 4217 individuals (respectively), using IPW adjustment to account for both 'being an internet survey respondent' and 'non-response in the follow-up survey' (details in online supplementary data). ${ }^{12} 1819$

Measures: current use (use in the previous 30 days)

Panellists were asked about their current use (use in the previous 30 days) of each product (e-cigarettes, Ploom, IQOS and glo) in the 2015, 2016 and 2017 surveys (glo was included in 2017 only, because it only entered the market in December 2016). The term 'Ploom Tech' was used instead of Ploom in 2017, following the product change. Respondents who answered 'yes' to the question, 'Have you used the following products in the previous 30 days?' (options: e-cigarette, Ploom, IQOS and glo) were defined as current users of the designated product(s). ${ }^{20} 21$ Current combustible cigarette smokers who had concurrently used any HNB tobacco or e-cigarette in the previous 30 days were defined as dual users.

\section{Measures: exposure to tobacco-related media information}

We examined whether people had seen the Ame-talk programme that introduced IQOS in the 2017 survey, using the question 'Have you seen the TV program "Ame Talk: The Latest Comedians' Tobacco Use”, which aired in April 2016? (yes or no)' with some capture images of the TV programme. Ame-talk is a popular programme that occasionally introduces new products such as home electrical goods, comic books and delicious foods, and broadcasts every Thursday night in Japan. A 1-hour episode broadcast on 28 April 2016, discussed comedians' tobacco use, focusing on IQOS (eg, what is IQOS, how to use tobacco including IQOS, smoking history and preferred brands). In the programme, a famous comedian said that residents in his apartment complex complained about him smoking on his veranda; to cope with this complaint, he had to change from cigarettes to IQOS. Other comedians discussed their dual use of IQOS and combustible cigarettes, and visually demonstrated its use, indicating a specific method to charge its battery. This programme introduced IQOS but did not mention Ploom or e-cigarettes.

Awareness of tobacco company promotions was also measured in the 2017 survey, using the question: 'How often have you noticed things that promote smoking?' Options included never, rarely, sometimes, often and very often. ${ }^{22}$

\section{Measures: symptoms from exposure to secondhand HNB tobacco aerosol}

Self-reported experience of, and symptoms due to, inhaling the aerosol produced by HNB tobacco devices used by other people were examined in the 2017 survey, using the questions: 'Have you ever inhaled the aerosol of HNB tobacco (Ploom Tech, IQOS and/or glo) that other people were using?' (yes or no) and 'Have you ever experienced symptoms due to the aerosol of HNB tobacco that other people were producing?'. Options included sore throat, eye pain, feeling ill and other injuries or symptoms (yes or no).

\section{Baseline characteristics in 2015}

Variables were grouped into demographics (age, sex, education, marital status and income), combustible and HNB tobacco/e-cigarette use history, use and intentions to quit, electronic smoking 


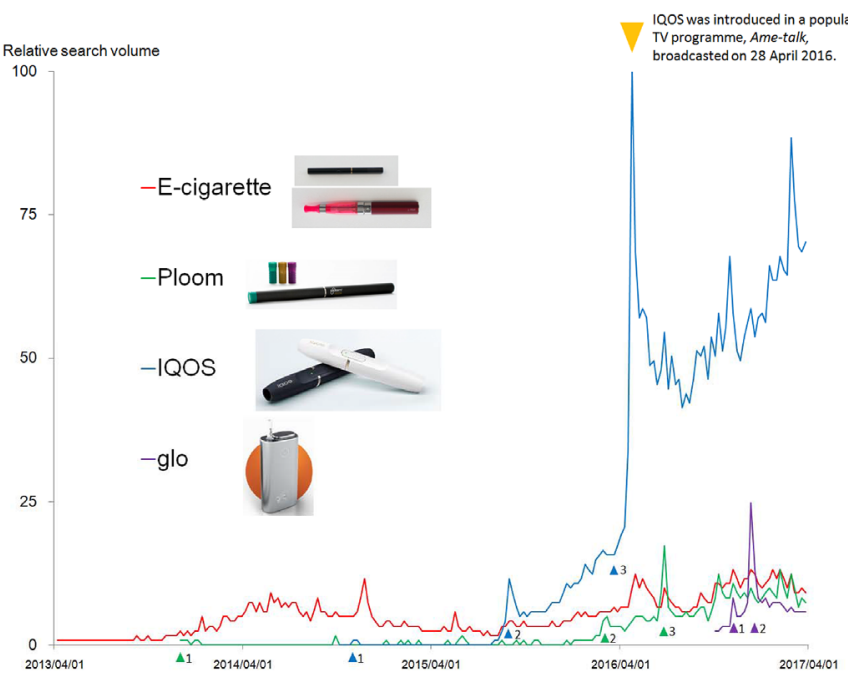

Figure 1 Weekly Google search volume for HNB tobacco/e-cigarette from 2013 to 2017 (past 4 years) in Japan. Note: Ploom sales began online in December 2013 ( $\boldsymbol{\Delta}$ green triangle no. 1) and Ploom Tech sales began in March 2016 ( $\boldsymbol{\Delta}$ green triangle no. 2), but both soon stopped because of product shortages. Ploom Tech sales restarted in June 2016 ( $\Delta$ green triangle no. 3). IQOS was sold only in Nagoya city as of November 2014 ( $\mathbf{\Delta}$ blue triangle no. 1), with expanded sales to 12 prefectures in September 2015 ( $\mathbf{\Delta}$ blue triangle no. 2), and further expansion to 35 prefectures in April 2016 ( $\Delta$ blue triangle no. 3). IQOS's results before November 2014 were omitted. British American Tobacco announced on 9 November 2016 (Apurple triangle no. 1) that glo would be sold from 12 December 2016 ( $\Delta$ purple triangle no. 2). glo's results before October 2016 were omitted. The above-mentioned information was reported by various news media, such as newspapers, television news and internet news. ※pictures were obtained from official websites except for the e-cigarette. Ame-talk: http://www. tvasahi.co.jp/ametalk/; Ploom: https://www.ploom.jp; IQOS: https:// www.iqos.jp; glo: https://www.discoverglo.com/jp. HNB, heat-not-burn.

device use history and intent, and worksite rules on tobacco use. Variables are described in the online supplementary data.

\section{Statistical analyses}

Weighted percentages and 95\% CIs for product use (e-cigarette, Ploom, IQOS and glo) in each of 2015, 2016 and 2017 were calculated, with IPW adjustments. Similarly, weighted percentages for self-reported symptoms from exposure to secondhand HNB tobacco aerosol in 2017 were calculated. Adjusted odds ratios (AORs) and 95\% CIs for HNB tobacco/e-cigarette use were calculated by multivariable logistic regression models with robust variance estimators to explore predictors of product use, using tobacco-related, sociodemographic and all other factors indicated in the above as covariates. Predictors of IQOS use in 2017 were examined, because considerable IQOS uptake was seen that year. Sex-stratified rates with 95\% CIs of use are shown in the online supplementary data. Probability values for statistical tests were two tailed; $\mathrm{P}<0.05$ was considered statistically significant. All analyses were performed using SAS V.9.3.

\section{RESULTS}

\section{Google Trends}

The weekly Google search volume for words related to HNB tobacco/e-cigarettes in Japan from 2013 to 2017 is shown in figure 1. Over this period, the highest RSV spike for IQOS (ie, RSV=100) was observed in the week of 24-30 April 2016, when IQOS was introduced in Ame-talk; after the spike, IQOS RSVs maintained high values. The second highest spike for IQOS (RSV=88) was observed in the week between 26 February 26 and 4 March 2017. This may be due to PMIs application in the USA, but this information was hardly reported as news. Therefore, cause of this spike is uncertain. For e-cigarettes, small spikes were occasionally seen, particularly around 2014, but there was no conspicuous upward trend. Also, small spikes corresponding to release time periods were observed for Ploom (RSV=17, 26 June to 2 July 2016) and glo (RSV=25, 11-17 December 2016). Aside from these spikes, IQOS had a markedly higher RSV than the other products (see online supplementary figure S1), which shows an RSV validation check using the stable term 'alcohol'.

\section{Longitudinal internet survey}

Characteristics of study participants are shown in table 1 (for all three waves in online supplementary table S1). Of total baseline subjects, $50 \%$ were male, $59 \%$ were never-smokers and $6 \%$ were ever-users of HNB tobacco/e-cigarette in 2015. Distribution of respondents in follow-up surveys was adjusted close to baseline distribution, using IPWs.

Estimated rates of current use (use in the previous 30 days) of HNB tobacco/e-cigarette in 2015, 2016 and 2017 are shown in table 2 and figure 1. In 2015, 1.3\% of respondents (both sexes) were current e-cigarette users, while $0.3 \%$ were current IQOS users (and similarly $0.3 \%$ for Ploom). One year later, in 2016, these levels had not changed greatly. In 2017, the e-cigarette current user rate had increased to $1.9 \%$, while the IQOS current user rate had increased more than 10 -fold to $3.6 \%$ (increased absolute value $=3.3 \%$ ). The Ploom Tech current user rate also increased, but only to $1.2 \%$, and the glo current user rate was $0.8 \%$ in 2017.

Men were more likely to use tobacco products than women (table 2 and see online supplementary tables S2-8). Baseline current smokers with intention to quit were significantly more likely to use IQOS than current smokers with no intention to quit $(18.8 \%$ vs $10.3 \%)$. Respondents who had seen the IQOS episode of Ame-talk in April 2016 were significantly more likely to use it than those who had not $(10.3 \%$ vs $2.7 \%)$; this tendency was also seen in dual users. In $2017,4.7 \%$ of respondents currently used at least one type of HNB tobacco or e-cigarette; of them, $72 \%$ also currently smoked combustible cigarettes-a $3.4 \%$ overall dual use rate.

Predictors of IQOS current use (use in the previous 30 days) in 2017 are shown in table 3. AOR of baseline current smokers with intention to quit was significantly higher than that of those with no intention to quit (13.3 vs 6.7$)$. AOR of respondents who had seen the TV programme was significantly higher (3.1) than that of those who had not. Women, aged 60 years or more, and current drinkers showed significantly lower AOR than reference categories. Ever-use or no use with preference of e-cigarette use, most deprived area of living place and experience of awareness of tobacco promotion were associated with greater odds of using IQOS.

We also examined and rejected the hypothesis that 'people who often watch TV may be more curious and therefore more likely to use new products'. Two sensitivity analyses, the first adjusting for everyday TV viewing and the second using subgroup analysis among those watching commercial TV programmes every day, did not change the results (data not shown; rather higher AORs were observed in those who saw the TV programme in these sensitivity analyses). 


\begin{tabular}{|c|c|c|}
\hline Characteristics at baseline 2015 & $\mathrm{n}^{*}$ & $\%$ \\
\hline Total & 8240 & 100.0 \\
\hline \multicolumn{3}{|l|}{ Sex } \\
\hline Men & 4084 & 49.6 \\
\hline Women & 4156 & 50.4 \\
\hline \multicolumn{3}{|l|}{ Age groups, years } \\
\hline 15-19 & 881 & 10.7 \\
\hline $20-29$ & 1462 & 17.7 \\
\hline $30-39$ & 1465 & 17.8 \\
\hline $40-49$ & 1487 & 18.1 \\
\hline $50-59$ & 1461 & 17.7 \\
\hline $60-69$ & 1484 & 18.0 \\
\hline \multicolumn{3}{|l|}{ Smoking status } \\
\hline Never-smoker & 4839 & 58.7 \\
\hline Former smoker & 1582 & 19.2 \\
\hline Current smoker with intention to quit & 281 & 3.4 \\
\hline Current smoker with no intention to quit & 1538 & 18.7 \\
\hline \multicolumn{3}{|l|}{ Workplace indoor smoking ban status } \\
\hline No ban (including smoking room/corner) & 2699 & 32.8 \\
\hline Complete ban & 3256 & 39.5 \\
\hline Not working/did not know & 2285 & 27.7 \\
\hline \multicolumn{3}{|l|}{ HNB tobacco/e-cigarette use status } \\
\hline Never used with no preference for e-cigarette use & 7369 & 89.4 \\
\hline Never used but would like to try e-cigarette in future & 353 & 4.3 \\
\hline Ever-user & 518 & 6.3 \\
\hline \multicolumn{3}{|l|}{ Equivalent household income } \\
\hline 1st quartile (lowest) & 2079 & 25.2 \\
\hline 2nd quartile & 1646 & 20.0 \\
\hline 3rd quartile & 1531 & 18.6 \\
\hline 4th quartile (highest) & 1256 & 15.2 \\
\hline Did not know/did not want to answer & 1729 & 21.0 \\
\hline \multicolumn{3}{|l|}{ Housing tenure } \\
\hline Does not own housing & 2237 & 27.2 \\
\hline Owns housing & 6003 & 72.9 \\
\hline \multicolumn{3}{|l|}{ Education } \\
\hline Junior high school/high school & 4905 & 59.5 \\
\hline University/technical school/college or more & 3335 & 40.5 \\
\hline \multicolumn{3}{|l|}{ Marital status } \\
\hline Married & 4970 & 60.3 \\
\hline Never married & 2802 & 34.0 \\
\hline Divorced/widowed & 468 & 5.7 \\
\hline \multicolumn{3}{|l|}{ Alcohol consumption } \\
\hline Never-drinker & 3360 & 40.8 \\
\hline Former drinker & 473 & 5.8 \\
\hline Current drinker & 4406 & 53.5 \\
\hline \multicolumn{3}{|l|}{ Self-rated health } \\
\hline Good (excellent/very good/good) & 7356 & 89.3 \\
\hline Poor (fair/poor) & 884 & 10.7 \\
\hline \multicolumn{3}{|l|}{ Area-level deprivation index of living place } \\
\hline 1st quartile (least deprived) & 1109 & 13.5 \\
\hline 2nd quartile & 1645 & 20.0 \\
\hline 3rd quartile & 2404 & 29.2 \\
\hline 4th quartile (most deprived) & 2862 & 34.7 \\
\hline Missing/unknown & 219 & 2.7 \\
\hline \multicolumn{3}{|l|}{ Experience of having seen the TV programmet‡ } \\
\hline Had not seen & 3756 & 45.6 \\
\hline
\end{tabular}

\begin{tabular}{|c|c|c|}
\hline Characteristics at baseline 2015 & $\mathrm{n}^{*}$ & $\%$ \\
\hline Had seen & 438 & 5.3 \\
\hline Did not respond to 2017 survey & 4046 & 49.1 \\
\hline \multicolumn{3}{|l|}{ Awareness of tobacco company promotiont } \\
\hline Never, seldom or sometimes seen & 3846 & 46.7 \\
\hline Often or very often seen & 153 & 1.9 \\
\hline $\begin{array}{l}\text { Did not respond to } 2017 \text { survey/responded to } \\
\text { reduced version§ }\end{array}$ & 4240 & 51.5 \\
\hline \multicolumn{3}{|c|}{$\begin{array}{l}\text { *Adjusted for 'being a respondent in an internet survey' using a nationally } \\
\text { representative sample in Japan. } \\
\text { †Information collected in } 2017 \text { survey. } \\
\text { ₹An episode of a popular entertainment TV show introducing IQOS, broadcasted on } \\
28 \text { April 2016, in Japan (see methods section for detail). } \\
\S^{\prime} \text { Responded to reduced version' means responders who answered the question- } \\
\text { reduced version that did not included some questions, such as on awareness of } \\
\text { tobacco company promotion ( } \mathrm{n}=194) \text {. Trends in current use of HNB tobacco/e- } \\
\text { cigarette, both sexes, in Japan. Longitudinal internet survey, 2015, } 2016 \text { and } 2017 . \\
\text { Note: rate of glo use in } 2015 \text { and } 2016 \text { (before glo's sales start) was } 0 \% \text {. HNB, } \\
\text { heat-not-burn. } \\
\text { HNB, heat-not-burn. }\end{array}$} \\
\hline
\end{tabular}

In all, $12 \%$ of respondents $(n=997)$ had been exposed to secondhand HNB tobacco aerosol (table 4). Of them, 37\% had experienced at least one symptom as a result, with the most common complaint being generally feeling ill, followed by eye discomfort and then a sore throat. Only $26 \%$ of current users reported having experienced at least one symptom, in comparison with $41 \%$ of former users and $49 \%$ of never-users of any tobacco product.

\section{DISCUSSION IQOS diffusion in Japan}

Interest in, and use of, IQOS among the Japanese rapidly increased from 2015 to 2017, triggered by its appearance on a popular national entertainment TV show, Ame-talk. Among viewers of the programme, IQOS use was nearly four times higher than non-viewers $(10.3 \%$ vs $2.7 \%)$. Although a substantial degree of influence from a popular TV show devoted to a product is to be expected from a marketing perspective, ${ }^{23}$ the impact of this single episode was nevertheless surprisingly large. This effect was confirmed by multivariable regression analyses (table 3) and Google Trends data (figure 2). Consistently, a recent study reported that number of Google searches for NHB tobacco in Japan exceeded that for e-cigarette in the USA. ${ }^{24}$ HNB tobacco are getting very popular. Previous literature shows that a new product or behaviour often has initial widespread popularity, as (1) influential 'early adopters' use the product and (2) more people are exposed to the product and find it compelling and that (3) the physical and social environment can be enormously influential in this regard. ${ }^{23} 25$ In Japan, (1) popular comedians played the role of early adopters, (2) IQOS was made by a wellknown tobacco company with the ability to promote it widely ${ }^{26}$ and (3) the spread of smoke-free environments in Japan might be influential. ${ }^{27}$ Several previous studies on e-cigarettes have shown that tobacco marketing and advertisement exposure may promote e-cigarette uptake, ${ }^{4}$ and the Ame-talk episode may thus have worked this way too. It is not known why only IQOS was introduced on television in this way. ${ }^{28}$

\section{Dual use is common}

Seventy-two per cent of HNB tobacco/e-cigarette current users also concurrently used combustibles. There is controversy over 


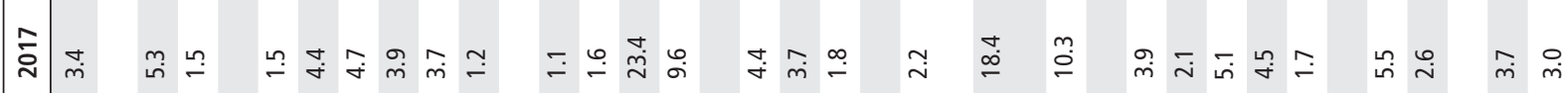

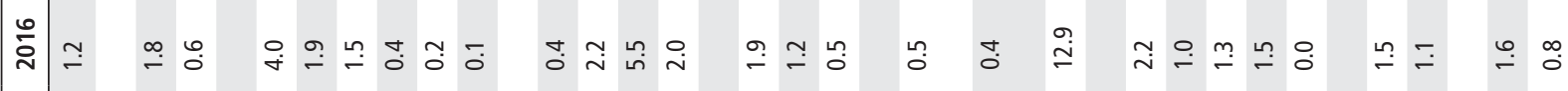
*

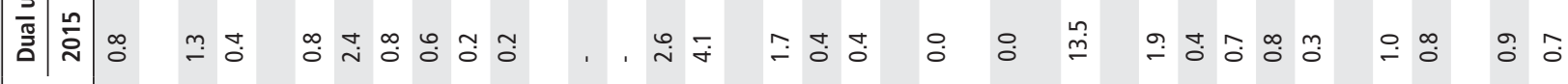

商

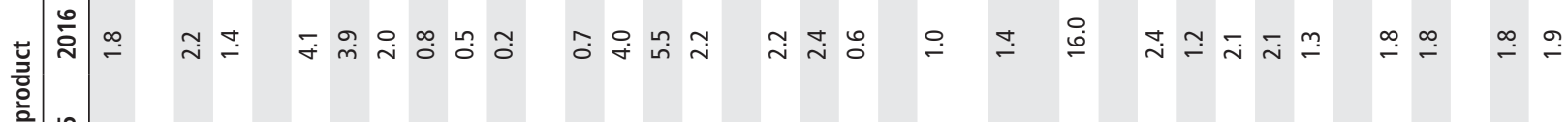

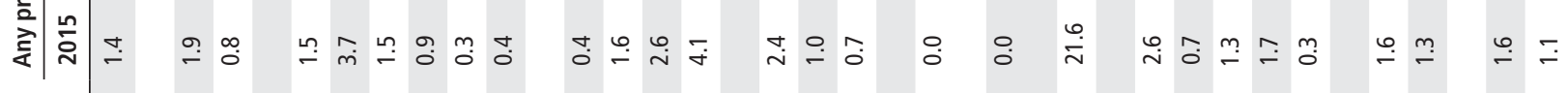

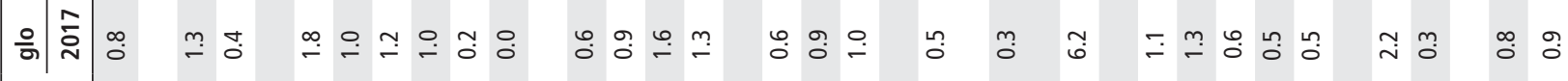

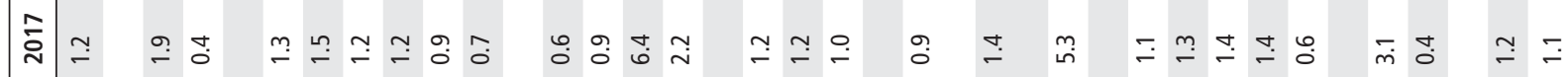

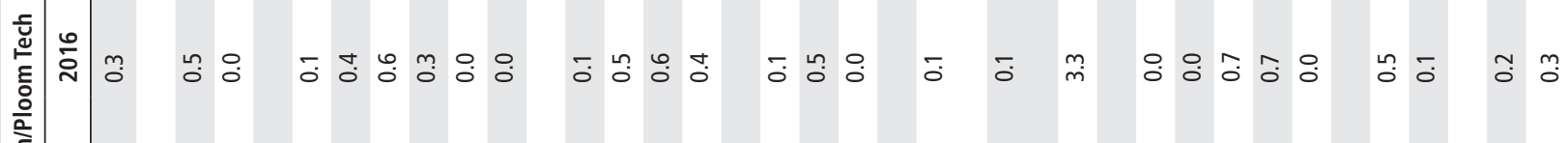

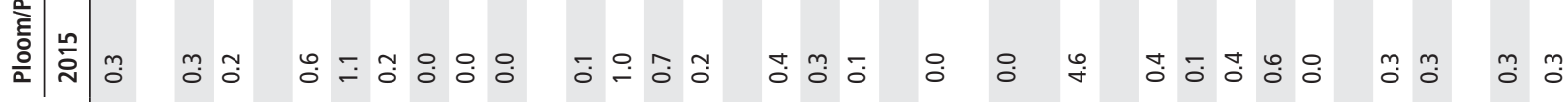

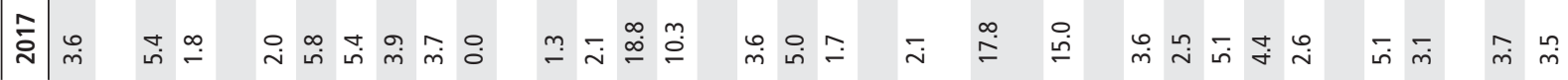

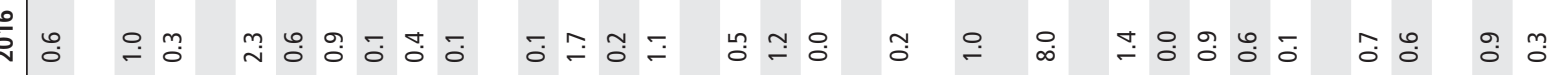

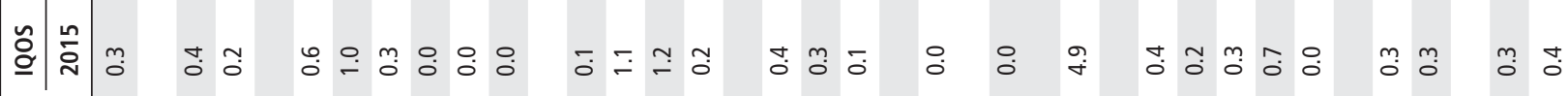

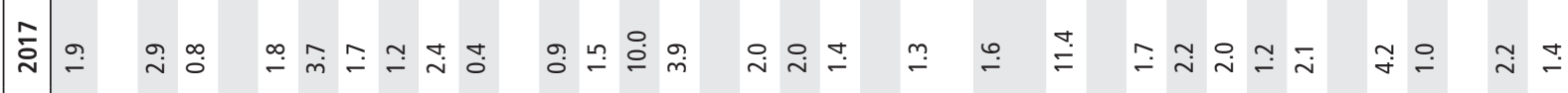



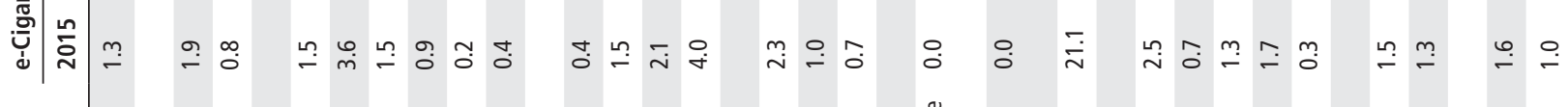

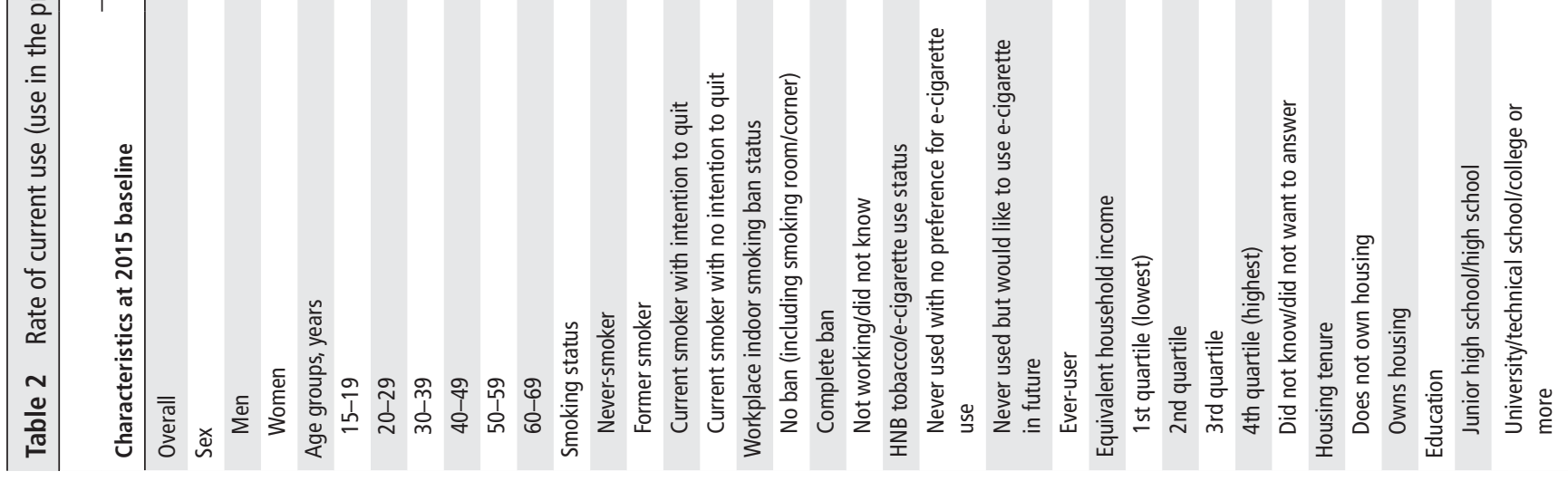




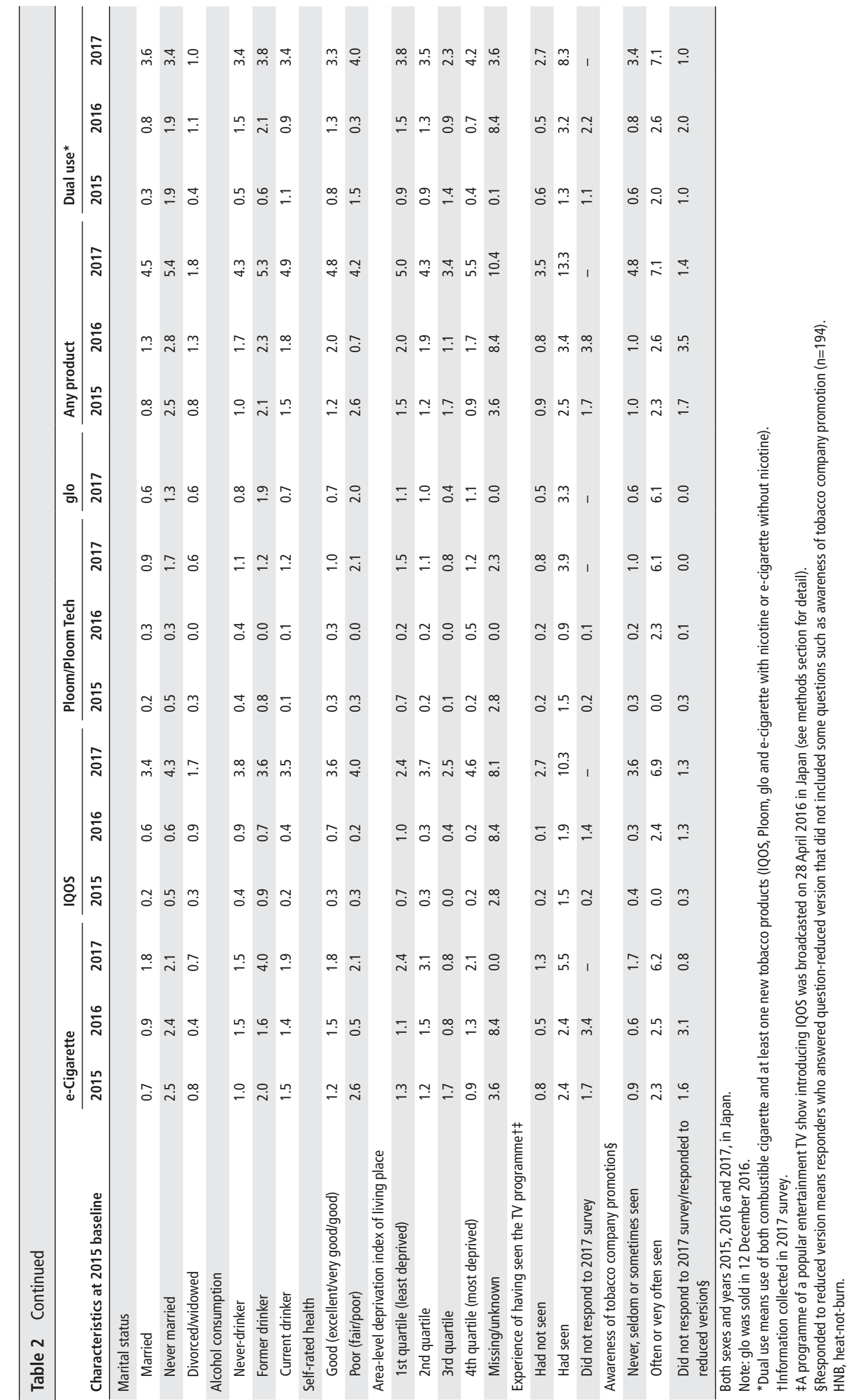


Table 3 Predictors of IQOS current use (IQOS use in the previous 30 days) in 2017 in Japan

\begin{tabular}{|c|c|c|}
\hline & Among total sample & $\begin{array}{l}\text { Among HNB tobacco/e- } \\
\text { cigarette never-users at } \\
\text { baseline }\end{array}$ \\
\hline $\begin{array}{l}\text { Characteristics at } 2015 \\
\text { baseline }\end{array}$ & Adjusted ORs* $(95 \% \mathrm{Cl})$ & Adjusted $\mathrm{ORs}^{*}(95 \% \mathrm{Cl})$ \\
\hline \multicolumn{3}{|l|}{ Sex } \\
\hline Men & 1 (reference) & 1 (reference) \\
\hline Women & $0.48(0.21$ to 1.05$)$ & $0.28(0.10$ to 0.77$)$ \\
\hline \multicolumn{3}{|l|}{ Age groups, years } \\
\hline $15-19$ & 1 (reference) & 1 (reference) \\
\hline $20-29$ & $1.88(0.53$ to 6.60$)$ & $2.76(0.76$ to 10.06$)$ \\
\hline $30-39$ & $1.53(0.36$ to 6.59$)$ & $1.58(0.32$ to 7.91$)$ \\
\hline $40-49$ & 0.81 (0.20 to 3.34$)$ & $1.20(0.29$ to 4.99$)$ \\
\hline $50-59$ & $1.25(0.25$ to 6.17$)$ & $1.36(0.24$ to 7.66$)$ \\
\hline $60-69$ & $0.01(0.00$ to 0.10$)$ & $0.00(0.00$ to 0.05$)$ \\
\hline \multicolumn{3}{|l|}{ Smoking status } \\
\hline Never-smoker & 1 (reference) & 1 (reference) \\
\hline Former smoker & $1.79(0.70$ to 4.60$)$ & $1.02(0.34$ to 3.03$)$ \\
\hline $\begin{array}{l}\text { Current smoker with } \\
\text { intention to quit }\end{array}$ & 13.3 (3.08 to 57.4$)$ & 18.5 (3.37 to 102.0$)$ \\
\hline $\begin{array}{l}\text { Current smoker with no } \\
\text { intention to quit }\end{array}$ & $6.74(2.52$ to 18.0$)$ & $11.4(3.98$ to 32.8$)$ \\
\hline \multicolumn{3}{|c|}{ Workplace indoor smoking ban status } \\
\hline $\begin{array}{l}\text { No ban (including smoking } \\
\text { room/corner) }\end{array}$ & 1 (reference) & 1 (reference) \\
\hline Complete ban & $1.58(0.65$ to 3.86$)$ & 1.76 (0.63 to 4.91$)$ \\
\hline Not working/did not know & 1.27 (0.45 to 3.55$)$ & $1.54(0.46$ to 5.19$)$ \\
\hline \multicolumn{3}{|c|}{ HNB tobacco/e-cigarette use status } \\
\hline $\begin{array}{l}\text { Never used with no } \\
\text { preference for e-cigarette } \\
\text { use }\end{array}$ & 1 (reference) & 1 (reference) \\
\hline $\begin{array}{l}\text { Never used but would like } \\
\text { to use e-cigarette in future }\end{array}$ & $4.16(1.44$ to 12.0$)$ & $3.58(1.26$ to 10.2$)$ \\
\hline Ever-user & $3.85(1.42$ to 10.5$)$ & - \\
\hline \multicolumn{3}{|l|}{ Equivalent household income } \\
\hline $\begin{array}{l}\text { 1st quartile } \\
\text { (lowest) }\end{array}$ & 1 (reference) & 1 (reference) \\
\hline 2nd quartile & 0.89 (0.30 to 2.62$)$ & $0.48(0.12$ to 1.85$)$ \\
\hline 3rd quartile & $1.79(0.70$ to 4.58$)$ & 1.69 (0.64 to 4.41$)$ \\
\hline 4th quartile (highest) & 2.09 (0.83 to 5.24$)$ & $1.72(0.63$ to 4.70$)$ \\
\hline $\begin{array}{l}\text { Did not know/did not want } \\
\text { to answer }\end{array}$ & 1.11 (0.27 to 4.52$)$ & 1.36 (0.38 to 4.89$)$ \\
\hline \multicolumn{3}{|l|}{ Housing tenure } \\
\hline $\begin{array}{l}\text { Does not own } \\
\text { housing }\end{array}$ & 1 (reference) & 1 (reference) \\
\hline Owns housing & $0.58(0.28$ to 1.19$)$ & 0.60 (0.27 to 1.33$)$ \\
\hline \multicolumn{3}{|l|}{ Education } \\
\hline $\begin{array}{l}\text { Junior high school/high } \\
\text { school }\end{array}$ & 1 (reference) & 1 (reference) \\
\hline $\begin{array}{l}\text { University/technical } \\
\text { school/college or more }\end{array}$ & 0.95 (0.41 to 2.23$)$ & 1.13 (0.43 to 2.95$)$ \\
\hline \multicolumn{3}{|l|}{ Marital status } \\
\hline Married & 1 (reference) & 1 (reference) \\
\hline Never married & 0.99 (0.47 to 2.10$)$ & 0.88 (0.38 to 2.07$)$ \\
\hline Divorced/widowed & 0.34 (0.05 to 2.27$)$ & 0.58 (0.08 to 3.99$)$ \\
\hline \multicolumn{3}{|l|}{ Alcohol consumption } \\
\hline Never-drinker & 1 (reference) & 1 (reference) \\
\hline Former drinker & 0.72 (0.20 to 2.57$)$ & 0.50 (0.11 to 2.35$)$ \\
\hline Current drinker & $0.44(0.18$ to 1.10$)$ & $0.34(0.13$ to 0.88$)$ \\
\hline
\end{tabular}

Continued
Table 3 Continued

\begin{tabular}{|c|c|c|}
\hline & Among total sample & $\begin{array}{l}\text { Among HNB tobacco/e- } \\
\text { cigarette never-users at } \\
\text { baseline }\end{array}$ \\
\hline \multicolumn{3}{|l|}{ Self-rated health } \\
\hline $\begin{array}{l}\text { Good (excellent/very good/ } \\
\text { good) }\end{array}$ & 1 (reference) & 1 (reference) \\
\hline Poor (fair/poor) & 1.42 (0.53 to 3.85$)$ & 1.95 (0.65 to 5.88$)$ \\
\hline \multicolumn{3}{|c|}{ Areal deprivation index of living place } \\
\hline $\begin{array}{l}\text { 1st quartile (least } \\
\text { deprived) }\end{array}$ & 1 (reference) & 1 (reference) \\
\hline 2nd quartile & 2.09 (0.77 to 5.70$)$ & $3.76(1.31$ to 10.8$)$ \\
\hline 3rd quartile & $1.38(0.52$ to 3.64$)$ & $1.32(0.39$ to 4.42$)$ \\
\hline $\begin{array}{l}\text { 4th quartile (most } \\
\text { deprived) }\end{array}$ & 2.79 (1.17 to 6.68$)$ & 3.41 (1.17 to 9.94$)$ \\
\hline Missing/unknown & 4.57 (1.14 to 18.3$)$ & $1.32(0.15$ to 11.37$)$ \\
\hline \multicolumn{3}{|c|}{ Experience of having seen the TV programmet‡ } \\
\hline Had not seen & 1 (reference) & 1 (reference) \\
\hline Had seen & $3.08(1.41$ to 6.70$)$ & 3.66 (1.65 to 8.08$)$ \\
\hline \multicolumn{3}{|c|}{ Awareness of tobacco company promotiont } \\
\hline $\begin{array}{l}\text { Never, seldom or } \\
\text { sometimes seen }\end{array}$ & 1 (reference) & 1 (reference) \\
\hline Often or very often seen & $2.44(0.75$ to 7.97$)$ & $3.03(1.00$ to 9.17$)$ \\
\hline $\begin{array}{l}\text { Responded to reduced } \\
\text { version§ }\end{array}$ & $0.63(0.16$ to 2.48$)$ & $0.76(0.16$ to 3.57$)$ \\
\hline \multicolumn{3}{|c|}{$\begin{array}{l}\text { "Adjusted for all listed variables. } \\
\text { †Information collected in } 2017 \text { survey. } \\
\text { ¥An episode of a popular entertainment TV show introducing IQOS, broadcasted on } \\
28 \text { April 2016, in Japan (see methods section for detail). } \\
\S^{\prime} \text { Responded to reduced version' refers to responders who answered a question- } \\
\text { reduced version that did not included some questions, such as on awareness of } \\
\text { tobacco company promotion ( } n=194) \text {. } \\
\text { HNB, heat-not-burn. }\end{array}$} \\
\hline
\end{tabular}

whether dual use of e-cigarettes can assist with smoking cessation or not, ${ }^{29-31}$ and there is no evidence that HNB tobacco products like IQOS currently play a role in cessation. We will examine this question using future follow-up survey data.

\section{Regulation of HNB tobacco/e-cigarettes}

Several regulatory issues are raised by the present findings. First, a significant portion of those exposed to secondhand HNB tobacco aerosol reported symptoms as a result. While the reported symptoms were mild, their frequency indicates that appropriate regulation will still be needed. Electronic tobacco products are regulated differently in Japan depending on whether they use tobacco leaf. The sale of nicotine-containing e-cigarettes as a pharmaceutical product in Japan was banned in 2010. Non-nicotine e-cigarettes, however, are unregulated and available to the public, even to minors. In contrast, Ploom, IQOS and glo are sold as tobacco products and regulated by the Tobacco Business Act, because components of these products are made of tobacco leaf. HNB tobacco products have been marketed to consumers as a less harmful alternative to conventional cigarettes, for both users and bystanders ${ }^{26}$; however, HNB tobacco aerosol does include various harmful constituents, although at lower levels than smoke from combustibles. ${ }^{32} 33$ Nicotine levels of HNB tobacco aerosol are approximately equal to those released by conventional cigarettes. ${ }^{1}{ }^{32} 33$ Moreover, their actual health effects on users and their overall impact on public health are still not fully known. ${ }^{34}$ Regulatory strategies for HNB tobacco should thus be carefully formulated with an eye towards the future. Regulators, however, are already far behind, 


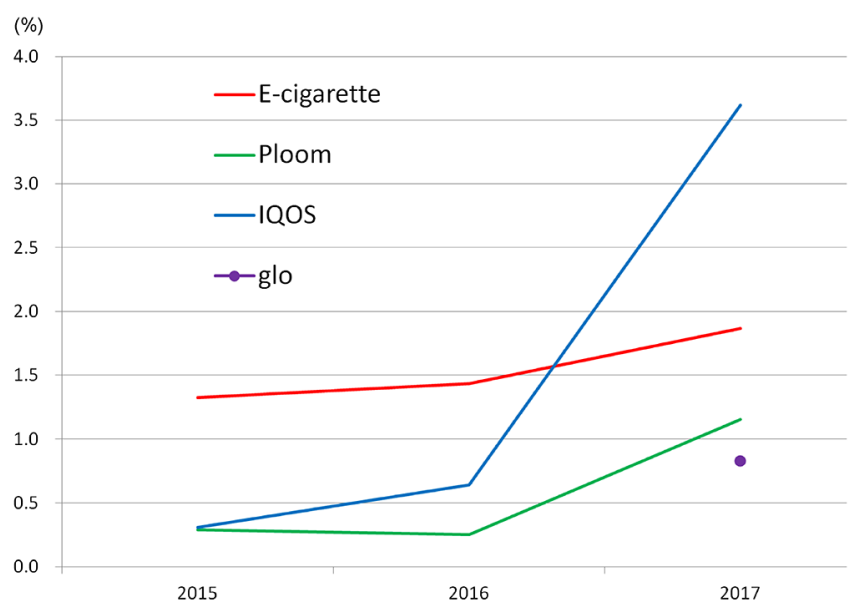

Figure 2 Trends in current use of HNB tobacco/e-cigarette, both sexes, in Japan. Longitudinal internet survey, 2015, 2016 and 2017. Note: rate of glo use in 2015 and 2016 (before glo's sales start) was 0\%. HNB, heat-not-burn.

because, as the present findings show, IQOS is already being widely used. If PMI gains FDA approval for IQOS in the USA, the company will assert that it poses reduced risk compared with combustibles and seek similar approvals worldwide. ${ }^{8}$

\section{Limitations and strengths}

Although the polling company seeks to ensure representativeness, the distribution is always imperfect; we adjusted for 'being an internet survey respondent' using nationally representative data. ${ }^{18}$ Additionally, self-reported information was used, and we excluded respondents with discrepancies or inconsistencies in the answers; however, since the true effects and implications of HNB tobacco/e-cigarette use are unknown, we could not confirm the validity of the exclusion and IPW adjustments in the study. Third, as HNB tobacco products looked like e-cigarettes, some people might categorise HNB tobacco, such as IQOS, as an e-cigarette. Therefore, some might have selected both e-cigarette and HNB tobacco, and this may have led to overestimation. Fourth, use in the previous 30 days was defined as current use in the present study as well as in previous studies. ${ }^{20}{ }^{21}$ Because use in the previous 30 days can include 1 day-only trials, cautious interpretation of the data is necessary. However, prevalence of 1 day-only use within 30 days was relatively small. In the present study, participants were asked 'For the previous 30 days, how many days did you use each tobacco product? (0 to 30 days)'. Of 298 users who reported IQOS use in the previous 30 days in 2017 , $52 \%$ used on 28 days or more, $22 \%$ used on 10-27 days and $14 \%$ used on 1 day. As these figures may differ by products and periods, we will report these details in the future. Fifth, Google Trends analysis showed its highest spike in the weekly data for 24-30 April 2016, when the Ame-talk episode on IQOS was broadcast in most areas. However, in some localities, it was not broadcast until May 2016; moreover, many people might have recorded the programme and watched it later, which may mean the spike was underestimated. Additional consideration of marketing efforts by the tobacco industry may be necessary.

Despite these limitations, this study garnered consistent results from two independent datasets-from Google Trends and a longitudinal internet survey. As this is the first study to report on the dissemination of IQOS, we need further monitoring and analysis of its impact in Japan.

\section{CONCLUSIONS}

A 1-hour entertainment TV programme triggered IQOS diffusion in Japan. In 2017, it was estimated that $3.6 \%$ of people currently used IQOS, while $4.7 \%$ currently used any HNB or e-cigarette product and 3.4\% were dual users. If these estimates are extrapolated straightforwardly to the 86 million Japanese adults aged 17-71 years, approximately 3.1 million currently use IQOS, 4.0 million currently use any $\mathrm{HNB}$ or e-cigarette product and 2.9 million are dual users. Tobacco control organisations and governments should continue to monitor HNB tobacco and consider how to regulate it, given its impending, likely rapid global diffusion.

Table 4 Symptoms caused by HNB tobacco aerosol produced by others

\begin{tabular}{|c|c|c|c|c|c|c|}
\hline \multirow[b]{2}{*}{ Characteristics } & \multirow{2}{*}{$\begin{array}{l}\text { Among total sample, } \mathrm{n}=8240 \\
\text { Exposed to aerosol of HNB tobacco, } \mathrm{n}(\%)\end{array}$} & \multicolumn{5}{|c|}{ Among those exposed to aerosol of HNB tobacco, $n=977$} \\
\hline & & Sore throat, \% & Eye pain, \% & Feeling ill, \% & Other injury or symptom, \% & Any symptom, \% \\
\hline Total & $977(11.9)$ & 20.6 & 22.3 & 25.1 & 13.4 & 37.0 \\
\hline \multicolumn{7}{|l|}{ Sex } \\
\hline Men & $582(14.1)$ & 19.7 & 24.0 & 24.3 & 18.6 & 31.4 \\
\hline Women & $395(9.6)$ & 21.9 & 19.9 & 26.3 & 5.7 & 45.3 \\
\hline \multicolumn{7}{|l|}{ Age groups, years* } \\
\hline $17-29$ & $179(10.6)$ & 27.9 & 37.3 & 39.7 & 14.5 & 56.3 \\
\hline $30-39$ & $310(18.5)$ & 22.3 & 25.0 & 24.0 & 13.6 & 42.1 \\
\hline $40-49$ & $227(12.0)$ & 22.4 & 22.3 & 25.1 & 11.0 & 28.8 \\
\hline $50-59$ & $169(12.2)$ & 11.6 & 5.7 & 12.0 & 18.8 & 24.4 \\
\hline $60-71$ & $93(5.8)$ & 13.0 & 14.9 & 24.8 & 6.6 & 26.1 \\
\hline \multicolumn{7}{|c|}{ Combustible cigarette and HNB tobacco/e-cigarette use* } \\
\hline Never/nevert & $294(6.9)$ & 23.1 & 28.7 & 38.0 & 9.6 & 49.2 \\
\hline $\begin{array}{l}\text { At least one former } \\
\text { and no current } ¥\end{array}$ & $272(13.1)$ & 21.1 & 20.9 & 22.9 & 10.6 & 41.2 \\
\hline At least one current§ & $412(21.5)$ & 18.6 & 18.7 & 17.4 & 18.0 & 25.6 \\
\hline
\end{tabular}

*Status in 2017.

†Never/never means persons who never smoke (combustible tobacco) and never use HNB tobacco/e-cigarette.

‡Former/former, former/never or never/former.

$\S$ Current/never, current/former, current/current, former/current or never/current.

HNB, heat-not-burn. 
What this paper adds

- In 2016, Philip Morris International applied for US Food and Drug Administration approval of the heat-not-burn tobacco product 'IQOS' as a modified risk tobacco product.

- Multiple heat-not-burn tobacco products (IQOS, Ploom Tech and glo) are currently sold in Japan, but prevalence of use for the products is unknown.

- To date, no studies have observed symptoms from exposure to secondhand heat-not-burn tobacco aerosol.

- Using Google search data and a longitudinal internet survey in Japan, we found that interest in, and use of, IQOS rapidly increased from 2015 to 2017 (use in the previous 30 days: $0.3 \%$ to $3.6 \%$ ), triggered by a 1 -hour popular entertainment TV show that introduced IQOS.

- Of participants who had been exposed to others' heatnot-burn tobacco aerosol, $37 \%$ had reported at least one symptom because of it.

- As heat-not-burn tobacco use rapidly increases, tobacco control organisations and governments should closely monitor the use of heat-not-burn tobacco and consider how to regulate it.

Acknowledgements We would like to thank Editage (www.editage.jp) for English language editing.

Contributors TT had full access to all of the data in the study and takes responsibility for the integrity of the data and the accuracy of the data analysis. Study concept and design: all authors; acquisition of data: TT and NK; analysis and interpretation of data: all authors; drafting of the manuscript: TT, SG and BC; critical revision of the manuscript for important intellectual content: all authors; statistical analysis: TT and TS; and study supervision: SG, TN, NK and BC.

Funding This work was supported by Health Labour Sciences Research Grants (H26-junkankitou-ippan-023, H28-junkankitou-ippan-002, H28-junkankitouippan-008 and H29-tokubetsu-shitei-006) and Japan Society for the Promotion of Science (JSPS) KAKENHI Grants (15H02964 and 15K19256). The work of SG was partially funded by the European Union's Horizon 2020 Research and Innovation Programme (The TackSHS Project; grant agreement: 681040).

Disclaimer The funding sources had no role in the design and conduct of the study; in the analysis and interpretation of the data; or in the preparation, review, or approval of the manuscript.

\section{Competing interests None declared.}

Ethics approval The study was reviewed and approved by the Research Ethics Committee of the Osaka International Cancer Institute (no. 1412175183).

Provenance and peer review Not commissioned; externally peer reviewed.

Data sharing statement Our rule for data sharing of raw data is under consideration.

Open access This is an open access article distributed in accordance with the Creative Commons Attribution Non Commercial (CC BY-NC 4.0) license, which permits others to distribute, remix, adapt, build upon this work non-commercially, and license their derivative works on different terms, provided the original work is properly cited and the use is non-commercial. See: http://creativecommons.org/ licenses/by-nc/4.0/

(c) Article author(s) (or their employer(s) unless otherwise stated in the text of the article) 2018. All rights reserved. No commercial use is permitted unless otherwise expressly granted.

\section{REFERENCES}

1 Farsalinos KE, Yannovits N, Sarri T, et al. Nicotine delivery to the aerosol of a heat-notburn tobacco product: comparison with a tobacco cigarette and e-cigarettes. Nicotine Tob Res 2017 (Epub ahead of print: 16 Jun 2017).

2 Philip Morris: Heated Tobacco Products. https://www.pmi.com/science-andinnovation/heated-tobacco-products (accessed 28 Oct 2017).

3 Grana R, Benowitz N, Glantz SA. E-cigarettes: a scientific review. Circulation 2014:129:1972-86.

4 Glasser AM, Collins L, Pearson JL, et al. Overview of electronic nicotine delivery systems: a systematic review. Am J Prev Med 2017;52:e33-66.
5 FDA Approval For iQOS To Be A Game Changer For Altria. 2016. https://www.forbes. com/sites/greatspeculations/2016/12/30/fda-approval-for-iqos-to-be-a-gamechanger-for-altria/\#bdb0d0e1a363 (accessed 12 May 2017).

6 Ministry of Health, Labour and Welfare. Comprehensive survey of living condition of people on health and welfare. Tokyo Health and Welfare Statistics Association. http:// www.mhlw.go.jp/toukei/list/20-21.html (accessed 26 Sep 2017)

7 Caputi TL. Industry watch: heat-not-burn tobacco products are about to reach their boiling point. Tob Control 2016;26:609-10.

8 Philip Morris International Seeks FDA Approval for iQ0S. 2017. http:// tobaccobusiness.com/philip-morris-international-seeks-fda-approval-iqos/ (accessed 12 May 2017).

9 U S Food \& Drug Administration. Q\&A: Modified Risk Tobacco Products. https://www. fda.gov/tobaccoproducts/labeling/tobaccoproductreviewevaluation/ucm410712.htm (accessed 17 Jun 2017).

10 Chapman S. Public health advocacy and tobacco control: making smoking history. Oxford, UK: Blackwell Publishing Ltd, 2007.

11 National Cancer Institute. Tobacco Control Monograph. The role of the media in promoting and reducing tobacco use. Bethesda, MD: U.S: Department of Health and Human Services, National Institutes of Health, National Cancer Institute.

12 Tabuchi T, Kiyohara K, Hoshino T, et al. Awareness and use of electronic cigarettes and heat-not-burn tobacco products in Japan. Addiction 2016;111:706-13.

13 Ayers JW, Althouse BM, Allem JP, et al. Revisiting the rise of electronic nicotine delivery systems using search query surveillance. Am J Prev Med 2016;50:e173-81

14 Ayers JW, Ribisl KM, Brownstein JS. Tracking the rise in popularity of electronic nicotine delivery systems (electronic cigarettes) using search query surveillance. Am J Prev Med 2011;40:448-53.

15 SEO Pack. Search Engine: Share in Japan. 2016. https://seopack.jp/seoblog/ 20160816-s-e-share/ (accessed 26 Sep 2017).

16 Ministry of Internal Affairs and Communication. Communications. Communications usage trend survey. 2015. http://www.soumu.go.jp/johotsusintokei/statistics/data/ 160722_1.pdf (accessed 9 Sep 2016)

17 Rakuten Research. Monitor profiles. 2015. http://research.rakuten.co.jp/en/ (accessed 11 Mar 2015).

18 Hoshino T. Statistics for observational data and surve data-Causal inference, selection bias and data fusion. Tokyo: Iwanami Shoten, 2009

19 Little RJ, D'Agostino R, Cohen ML, et al. The prevention and treatment of missing data in clinical trials. N Engl J Med 2012;367:1355-60.

20 Giovenco DP, Lewis MJ, Delnevo CD. Factors associated with e-cigarette use: a national population survey of current and former smokers. Am J Prev Med 2014:47:476-80

21 King BA, Patel R, Nguyen $\mathrm{KH}$, et al. Trends in awareness and use of electronic cigarettes among US adults, 2010-2013. Nicotine Tob Res 2015;17:219-27.

22 Kasza KA, Hyland AJ, Brown A, et al. The effectiveness of tobacco marketing regulations on reducing smokers' exposure to advertising and promotion: findings from the International Tobacco Control (ITC) Four Country Survey. Int J Environ Res Public Health 2011:8:321-40.

23 Glanz K, Rimer BK, Viswanath K. Health behavior and health education: theory, research, and practice. 4th edition. San Francisco: USA Jossey-Bass A Wiley Imprint, 2008.

24 Caputi TL, Leas E, Dredze M, et al. They're heating up: Internet search query trends reveal significant public interest in heat-not-burn tobacco products. PLoS One 2017;12:e0185735.

25 Gladwell M. The Tipping Point: How Little Things Can Make a Big Difference. Boston: Back Bay Books, 2002.

26 Lüdicke F, Picavet P, Baker G, et al. Effects of switching to the menthol tobacco heating system 2.2, smoking abstinence, or continued cigarette smoking on clinically relevant risk markers: a randomized, controlled, open-label, multicenter study in sequential confinement and ambulatory settings (Part 2). Nicotine Tob Res 2017 (Epub ahead of print: 9 Feb 2017).

27 Tabuchi T, Colwell B. Disparity and trends in secondhand smoke exposure among japanese employees, particularly smokers vs. Non-smokers. PLoS One 2016:11:e0152096.

28 Lambert A, Sargent JD, Glantz SA, et al. How philip morris unlocked the japanese cigarette market: Lessons for global tobacco control. Tob Control 2004;13:379-87.

29 Kalkhoran S, Glantz SA. E-cigarettes and smoking cessation in real-world and clinical settings: a systematic review and meta-analysis. Lancet Respir Med 2016:4:116-28.

30 Yeh JS, Bullen C, Glantz SA. Clinical decisions. E-cigarettes and smoking cessation. N Engl J Med 2016;374:2172-4

31 Hartmann-Boyce J, McRobbie H, Bullen C, et al. Electronic cigarettes for smoking cessation. Cochrane Database Syst Rev 2016;9:CD010216

32 Bekki K, Inaba Y, Uchiyama S, et al. Comparison of chemicals in mainstream smoke in heat-not-burn tobacco and combustion cigarettes. J Uoeh 2017;39:201-7.

33 Auer R, Concha-Lozano N, Jacot-Sadowski I, et al. Heat-not-burn tobacco cigarettes: smoke by any other name. JAMA Intern Med 2017;177:1050-2.

34 Kiyohara K, Tabuchi T. Electronic cigarette use in restaurants and workplaces where combustible tobacco smoking is not allowed: an Internet survey in Japan. Tob Control 2017 (Epub ahead of print: 12 Jun 2017). 